\title{
Aetiological investigations in early developmental impairment: are they worth it?
}

\author{
Anthony Richard Hart, ${ }^{1}$ Ruchi Sharma, ${ }^{2}$ Mark Atherton, ${ }^{3}$ Samer Alabed, ${ }^{4}$ \\ Sally Simpson, ${ }^{3}$ Stuart Barfield ${ }^{3}$ Judith Cohen, ${ }^{5}$ Nicholas McGlashan, ${ }^{4}$ Asha Ravi, ${ }^{6}$ \\ Michael James Parker, ${ }^{7}$ Daniel JA Connolly ${ }^{4}$
}

\begin{abstract}
- Additional material is published online only. To view please visit the journal online (http://dx.doi.org/10.1136/ archdischild-2017-312843)

For numbered affiliations see end of article.
\end{abstract}

Correspondence to Dr Anthony Richard Hart, Department of Paediatric and Neonatal Neurology, Sheffield Children's Hospital NHS Foundation Trust, Ryegate Children's Centre, Tapton Crescent Road, Sheffield $\mathrm{S10}$ 5DD, UK; anthony.hart@sch.nhs.uk

Received 6 February 2017 Revised 16 May 2017

Accepted 25 May 2017 Published Online First 22 July 2017

\section{Linked}

- http://dx.doi.org/10.1136/ archdischild-2017-312738

- http://dx.doi.org/10.1136/ archdischild-2017-312739

- http://dx.doi.org/10.1136/ archdischild-2016-311271

- http://dx.doi.org/10.1136/ archdischild-2017-313415

- http://dx.doi.org/10.1136/

archdischild-2017-313532

CrossMark

To cite: Hart AR, Sharma R,

Atherton $\mathrm{M}$, et al.

Arch Dis Child

2017:102:1004-1013.

\begin{abstract}
Objective To study the frequency a diagnosis is made in children with early developmental impairment (EDI), and the contribution made to diagnosis by specific investigations.

Design Retrospective case note review.

Setting Community, neurodisability and neurology department at a UK tertiary centre.

Participants Children referred to determine the aetiology of EDI where a cause was not evident on history and examination. Participants were divided into two groups: EDI and no additional features (EDI-) and EDI with additional features (EDI+).
\end{abstract}

Main outcome measures The frequency a cause was found for the child's EDI and which tests contributed to a diagnosis.

Results 699 participants, $68.8 \%$ boys, median age at investigation 2 years 8 months (range 3 months to 11 years 5 months). 61 (8.7\%) of participants had no investigations, and children with EDI- were less likely to be investigated $\left(\chi^{2}=12.5, p<0.05\right)$. A diagnosis was made in 166 children $(23.7 \%)$ and was more frequent in $E D I+\left(E D I-9.9 \%, E D I+27.3 \%, \chi^{2}=19.0 ; p<0.05\right)$. Full blood count, zinc protoporphyrin, renal or liver function, bone profile, biotinidase, creatine kinase or lead level revealed no diagnoses. The following investigations found causes for EDI: MRI (23.1\%), microarray (11.5\%), Fragile $X(0.9 \%)$, plasma amino acids $(1.2 \%)$, urine organic acids (0.9\%) and thyroid function tests $(0.5 \%)$. Conclusions The majority of 'screening' investigations for EDI do not contribute to a diagnosis, highlighting an area of cost saving for the NHS and reduced burden for patients and families. We propose a streamlined guideline for the investigation of EDI based on our data.

\section{INTRODUCTION}

Early developmental impairment (EDI) occurs when a child's developmental skills fall 2 SD or more below the population mean in two or more developmental domains. ${ }^{12}$ Ten per cent to $12 \%$ of children have a developmental impairment, ${ }^{34}$ and $1 \%-3 \%$ of children have EDI. ${ }^{13}$ The causes of EDI include genetic, metabolic, antenatal, endocrine and infective conditions, among others. The number of recommended investigations has increased over the last 20 years, ${ }^{13-16}$ although opinion varies on whether children with EDI are investigated appropriately, and the usefulness of specific investigations. ${ }^{17}$ This work aims to determine the frequency an aetiology was found for EDI, and the contribution of individual investigations.
What is already known on this topic?

- Early developmental impairment (EDI) is a common reason for referral to paediatricians and has many different aetiologies.

- Few of the aetiologies of EDI are treatable, but discovering the cause is important to families and helps predict recurrence risk.

- Recent recommendations suggest a battery of tests to determine the aetiology of EDI, but little data exist on the effectiveness of these tests.

\section{What this study adds?}

- The majority of recommended aetiological investigations do not reveal a cause for EDI.

- First-line investigations should include microarray and thyroid function. Creatine kinase could help identify Duchenne muscular dystrophy in boys.

- Other investigations should be reserved as second line, unless additional features exist or a strong suspicion of a specific condition exists.

\section{METHODS}

Patient identification

Children with EDI referred to Community Paediatrics, Neurodisability or Neurology services in Sheffield between January 2010 and December 2015 were identified by searching clinic letter databases. Children were included if the referral was to assess the level of EDI or determine cause. Children were not included if they were referred for another reason, such as epilepsy management, or if the cause was obvious on initial assessment. Although the term 'early developmental impairment' typically refers to children under 5 years of age, with intellectual or learning disability reserved for older children, we have included older children in our study because a small number of our referrals were children who had developmental impairment from a young age but did not have access to medical services or investigations until they moved to the UK.

\section{Clinical phenotype and investigation results}

Data were extracted from clinical notes including basic patient characteristics, investigations performed and investigation results. Clinical 
features were noted and two groups established: EDI without additional features (EDI-) and EDI with additional features $(E D I+)$. Subgroups of additional features were formed if the feature was thought clinically relevant and affected at least five participants.

Four paediatricians reviewed participants' investigation results to determine the cause of their EDI. Results were categorised as:

- normal

- abnormal, but non-diagnostic (for example just outside the reference range)

$\checkmark$ diagnostic.

Where doubt existed about the categorisation of the investigation, the first author was the final arbiter.

Two neuroradiologists reviewed participants' neuroimaging and categorised them as:

- 'normal'

- 'specific abnormalities explaining the participant's EDI or pointing towards a diagnosis'

- 'specific or non-specific abnormalities that did not suggest an aetiology'. ${ }^{18}$

A consultant paediatric neuroradiologist was the final arbiter on categorisation.

An investigation was considered to contribute to the diagnosis if it explained the cause of a child's EDI or allowed parents to comprehend the problem and the child to access educational support, as per Makela et al. ${ }^{19}$ Non-aetiological findings were considered diagnostic, such as 'cortical brain malformation', as were tests pointing towards a diagnosis proven on another investigation.

\section{Statistical analysis}

We report the frequency participants received the investigations recommended in our hospital guideline (online supplementary table 1), the frequency each test was diagnostic and differences in the frequency of diagnostic investigations between groups using a $\chi^{2}$ test calculated with an online $\chi^{2}$ generator. A p value $<0.05$ was assumed statistically significant.

\section{Governance}

The Clinical Governance department approved this work as a service evaluation. Data were collected in an anonymised format. No ethical approval was required.

\section{RESULTS}

\section{Participant characteristics}

Seven hundred and fifteen participants were referred over our 6-year period. Sixteen participants were excluded because either a diagnosis was obvious or insufficient clinical details were available. 481/699 (68.8\%) participants were boys, 218 (31.2\%) girls. Median age at time of investigation was 2 years 8 months (range 3 months to 11 years 5 months). A cause was found in $166(23.7 \%)$ participants (table 1$)$.

\section{Investigation and diagnosis rates}

61/699 (8.7\%) participants had no investigations: 23/142 (16.2\%) participants with EDI- and 38/557 (4.1\%) with EDI+ $\left(\chi^{2}=12.5, p<0.05\right)$. The local guideline was followed in entirety in $45(6.4 \%)$ participants. A diagnosis was made in 14/142 (9.9\%) children with EDI- and 152 (27.3\%) with EDI $+\left(\chi^{2}=19.0 ; p<0.05\right)$. The additional features are shown in online supplementary figure $1 \mathrm{a}$ and the proportion of diagnoses for each additional feature in online supplementary figure $1 \mathrm{~b}$.

\section{Results of specific investigations}

The proportion of participants receiving each investigation on our guideline is shown in table 1 . None of the following contributed to a diagnosis: full blood count, zinc protoporphyrin/ haematinics, renal or liver function, bone profile, biotinidase, creatine kinase, lead level or urine GAGs.

During our study period, karyotype was replaced by Comparative genomic hybridization (CGH) microarray. 430/669 (64.3\%) participants had a microarray only, 84 (12.0\%) karyotype analysis only and $12(1.7 \%)$ had microarray and karyotype analysis. Of the 442 participants who had microarray testing, $51(11.5 \%)$ were diagnostic and $49(11.1 \%)$ were a non-diagnostic abnormal result, such as polymorphisms or results of uncertain significance (online supplementary table 2). Participants with EDI+ were more likely to receive microarray testing $\left(65.2 \%\right.$ vs $\left.55.6 \%, \chi^{2}=4.4 ; \mathrm{p}<0.05\right)$, but diagnostic rates were similar between groups (EDI- $11.4 \%$, EDI $+11.6 \%\left(\chi^{2}=0.0\right.$; $\mathrm{p}=0.96)$ ). Table 2 and online supplementary figure $1 \mathrm{c}$ show the proportion of diagnostic microarrays for each additional feature. Participants with dysmorphia had similar diagnostic rates to participants with EDI+ but no dysmorphia (11.8\% vs $11.5 \%, \chi^{2}=0.2 ; p=0.66$ ).

Fragile X was requested in 113/699 (16.2\%) participants, 32 of whom had a family history of learning/developmental difficulties. Fragile $\mathrm{X}$ was abnormal in one case: a 2-year-old boy with no family history or additional features. Genetic diagnoses were made following review by a clinical geneticist or specific gene analysis (online supplementary table 2).

Thyroid function was diagnostic in three participants, all of whom had additional features (table 1), and were autoimmune in aetiology. Plasma amino acid screens were diagnostic in five participants and urine organic acids in three, two of whom had abnormal plasma amino acids. Clinicians ordered a variety of other investigations (table 3 ) and revealed a diagnosis in five participants.

\section{Neuroimaging}

MR imaging was performed in 368/699 (52.6\%) participants. Children with EDI+ were more likely to receive neuroimaging compared with EDI- (additional features $60.7 \%$ vs $21.1 \%$ for no additional features, $\left.\chi^{2}=71.0 ; \mathrm{p}<0.05\right)$. MRI was diagnostic in $85(23.1 \%)$ participants: $81 / 338(24.0 \%)$ participants with EDI+ and $4 / 30(13.3 \%)$ EDI- $\left(\chi^{2}=1.8 ; p=0.18\right)$. Table 4 shows the distribution of abnormalities found on MR imaging and online supplementary figure $1 \mathrm{~d}$ shows the frequency of abnormalities for additional feature subgroups.

\section{DISCUSSION}

\section{Why investigate for the cause of EDI?}

The reasons why families wish to know the aetiology include ${ }^{19}$ :

- validation, that is, proof of a credible problem and to explain the problem to others;

- to provide prognostic information and help set realistic expectations/plans;

- for potential treatments;

- to allow access to educational support;

- to allow for early intervention;

- to provide support opportunities;

- the 'need to know';

- to end the 'diagnostic odyssey';

- for prenatal testing and recurrence risk.

Not all diagnoses are equally effective at enabling access to educational support despite children having similar levels of 


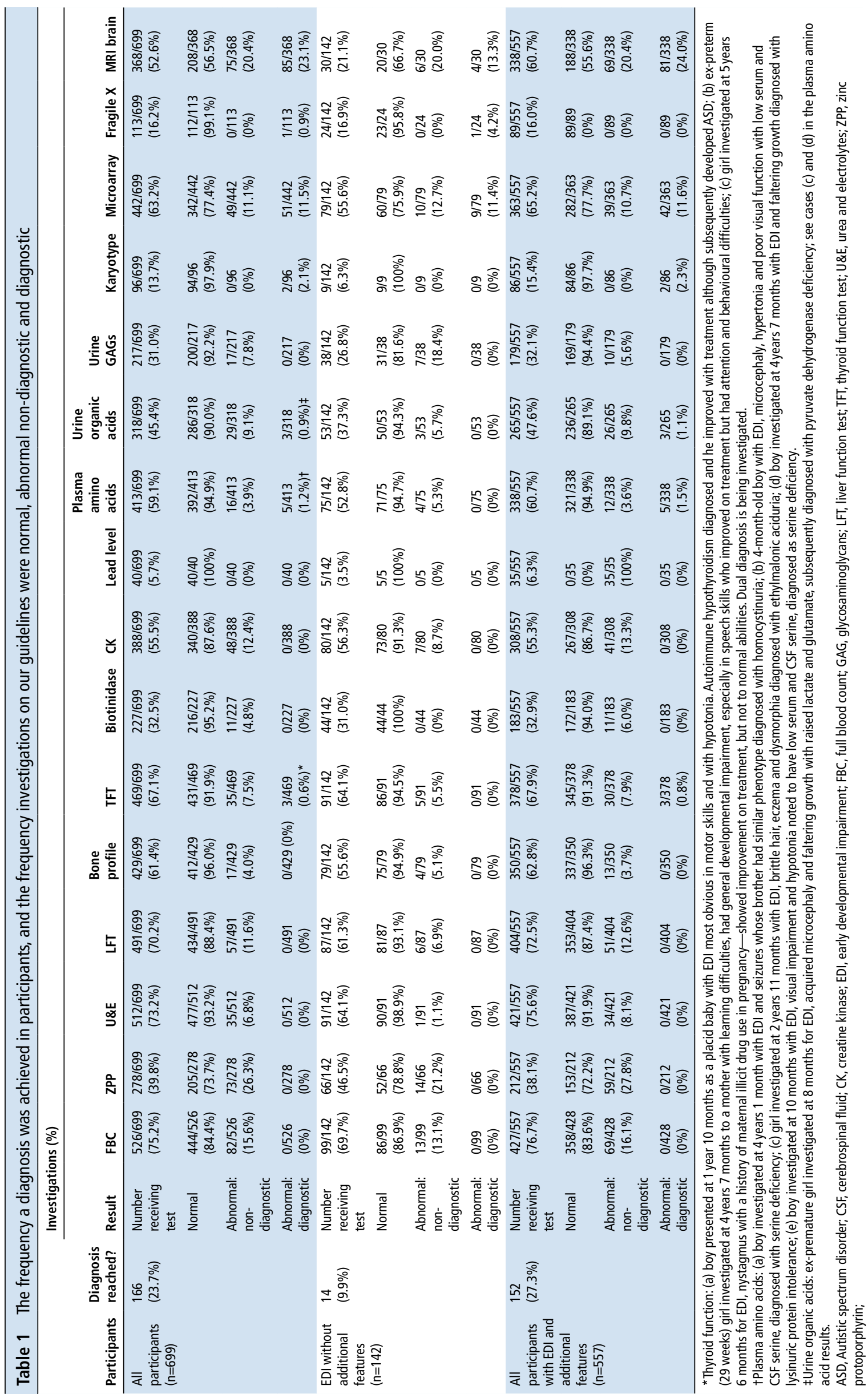




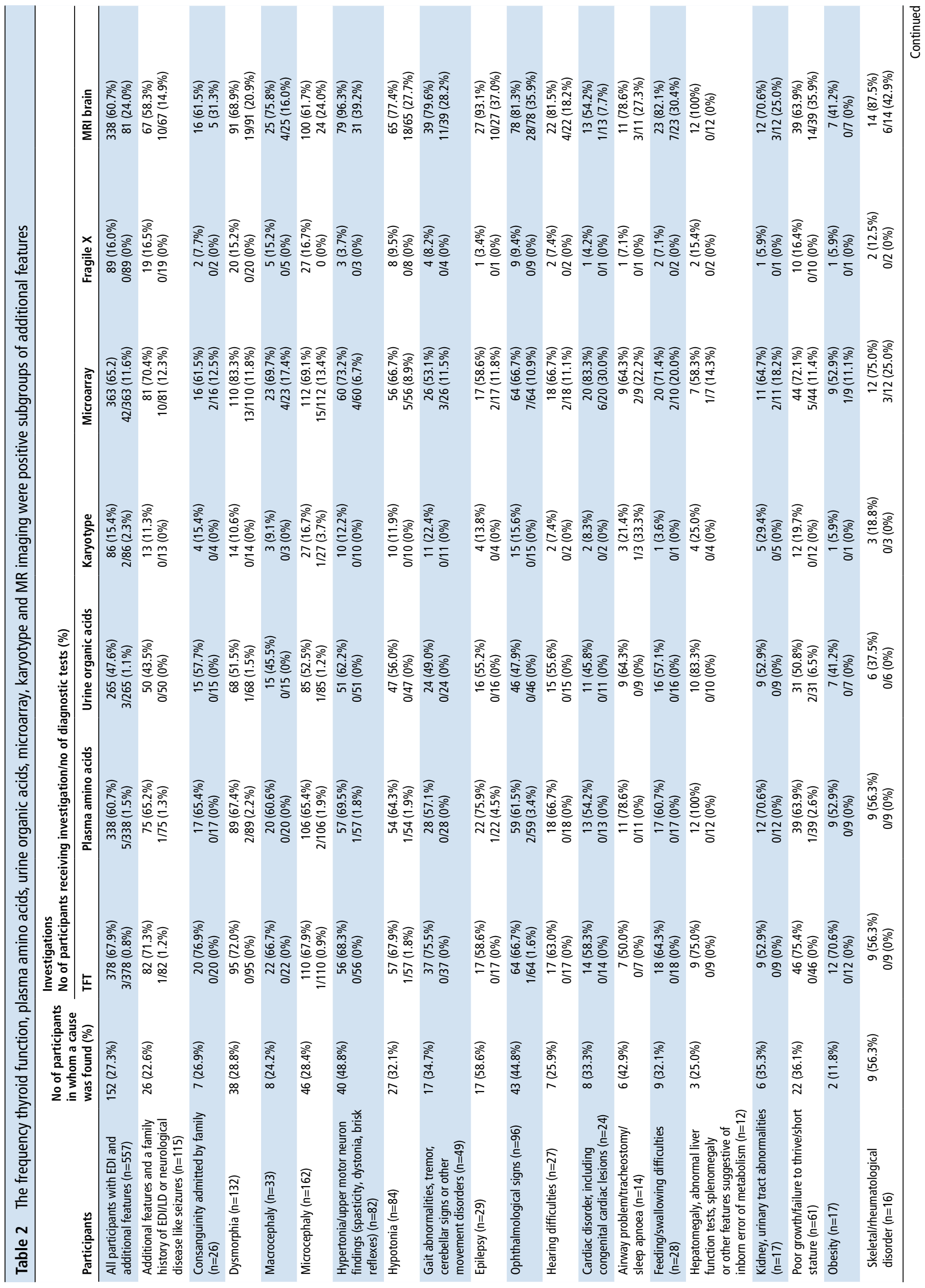




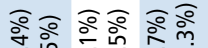
ษั

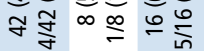

disability. Descriptive diagnoses could be equally, if not more, effective than aetiological diagnoses.

\section{Investigating the cause of EDI}

The initial steps to investigate children with EDI are history and examination, and an assessment of hearing should also be considered early. The effect of the child's environment, including poverty, parental educational levels, employment status and family status, needs to be taken into account and addressed. In some situations, these may need to be tackled before investigations are undertaken.

In cases where no clear cause for the child's EDI is evident on initial assessment, there is little agreement on the best investigations to perform, with wide variation in opinion existing between UK paediatricians. ${ }^{17}$ Over the years, the number of recommended investigations for EDI has increased, ${ }^{13}$ 5-16 although the evidence base for this is lacking. The low adherence to our clinical guideline reflects clinician uncertainty about the optimal way to investigate children with EDI.

A cause was found in $23.7 \%$ of our participants. This may have been a result of a single test or a contribution of many. Many of the first-line investigations in our guideline were of no value in determining an aetiology.

Biotinidase level is recommended in some guidelines. ${ }^{3}{ }^{12}$ The features of biotinidase deficiency include seizures, hypotonia, laryngeal stridor, tachypnoea, apnoea, alopecia, skin rash, hearing loss, optic atrophy or conjunctivitis, ataxia, fungal infection, recurrent myelopathy, hyperammonaemia or specific organic acid abnormalities. ${ }^{20-24}$ It is not clear that biotinidase deficiency presents with EDI- ${ }^{25}$ The incidence of biotinidase deficiency on newborn screening suggests is low. ${ }^{20}$ Recommendations that routine testing is cost-effective ${ }^{26}$ are not evidence based. Our view is that serum biotinidase should only be performed second or third line in children with suggestive features.

High blood lead levels are associated with learning and mental health issues that can persist into adulthood. ${ }^{27}{ }^{28}$ Low levels of blood lead $(5-10 \mu \mathrm{g} / \mathrm{dL})$ are associated with reading and writing difficulties. ${ }^{29}$ However, it is unlikely that a modern child would have moderate or severe EDI because of extremely high lead levels alone, and the proportion of children with high lead levels has fallen to $0.8 \%$ in the USA. ${ }^{3031}$ Therefore, routine lead levels appear to be unnecessary.

Creatine kinase $(\mathrm{CK})$ is recommended in boys with EDI to facilitate early diagnosis of Duchenne muscular dystrophy (DMD), ${ }^{3}{ }^{12}$ ensure treatment with steroids and/or newer drugs, and for entry into research studies. These children may present with EDI or social communication difficulties before muscle weakness is appreciated, so clinical phenotype cannot be relied on to trigger testing. Although no child in our study had DMD, it is our opinion that DMD is common and a CK cheap enough for it be performed routinely in boys with EDI.

\section{Investigations likely to determine the cause of EDI}

The investigations that contributed to a diagnosis were:

- thyroid function

- plasma amino acids

- urine organic acids

- microarray/karyotype

- Fragile X

- MR imaging.

Congenital hypothyroidism is usually diagnosed on newborn screening in the UK, unless it arises from pituitary failure. Autoimmune hypothyroidism will also be missed. The cost of each 
Table 3 Number of participants receiving additional investigations

\begin{tabular}{|c|c|c|}
\hline Investigation & No of participants (\% of total) & Comments \\
\hline \multicolumn{3}{|l|}{ Blood investigations } \\
\hline Clotting & 5 & $\begin{array}{l}\text { Abnormal in one patient, but already known to be abnormal prior to } \\
\text { referral for investigation of EDI }\end{array}$ \\
\hline Folate & 8 & Not diagnostic in any participant \\
\hline $\mathrm{C}$ reactive protein & 1 & Not diagnostic in any participant \\
\hline Erythrocyte sedimentation rate & 4 & Not diagnostic in any participant \\
\hline Glucose & 58 & No abnormalities \\
\hline Lactate & 178 & $\begin{array}{l}\text { Persistently abnormal in one boy investigated at } 1.4 \text { years of age with } \\
\text { dysmorphia, pulmonary stenosis, squint and hypertonia; MRS showed } \\
\text { lactate peak although respiratory chain enzymes normal and no genetic } \\
\text { diagnosis of mitochondrial disease made }\end{array}$ \\
\hline Acylcarnitine screen & 100 & Not diagnostic in any participant \\
\hline Magnesium & 3 & Not diagnostic in any participant \\
\hline Ammonia & 67 & Not diagnostic in any participant \\
\hline Homocysteine & 11 & Not diagnostic in any participant \\
\hline Uric acid & 103 & Not diagnostic in any participant \\
\hline Lipid/cholesterols & 40 & Not diagnostic in any participant \\
\hline White cell enzymes & 45 & Not diagnostic in any participant \\
\hline Very long chain fatty acids & 60 & Not diagnostic in any participant \\
\hline Transferrin isoelectric focusing & 46 & Not diagnostic in any participant \\
\hline Galactosaemia screen & 15 & Not diagnostic in any participant \\
\hline Copper & 21 & Not diagnostic in any participant \\
\hline Caeruloplasmin & 20 & Not diagnostic in any participant \\
\hline Free T3 & 9 & Not diagnostic in any participant \\
\hline Cortisol & 12 & Not diagnostic in any participant \\
\hline Vitamin A & 7 & Not diagnostic in any participant \\
\hline Vitamin $B_{12}$ & 10 & Not diagnostic in any participant \\
\hline Vitamin D & 193 & $\begin{array}{l}\text { Low levels were not felt to be the aetiological cause of EDI in any } \\
\text { participant }\end{array}$ \\
\hline Vitamin $\mathrm{E}$ & 9 & Not diagnostic in any participant \\
\hline Coeliac screen & 40 & Not diagnostic in any participant \\
\hline Amylase & 5 & Not diagnostic in any participant \\
\hline Parathyroid hormone & 48 & Not diagnostic in any participant \\
\hline Immunoglobulins & 42 & Not diagnostic in any participant \\
\hline LDH & 3 & Not diagnostic in any participant \\
\hline Alpha fetoprotein & 5 & Not diagnostic in any participant \\
\hline ANA & 4 & Not diagnostic in any participant \\
\hline Rheumatoid factor & 2 & Not diagnostic in any participant \\
\hline Congenital infection screen & 34 & Not diagnostic in any participant \\
\hline \multicolumn{3}{|l|}{ Urine investigations } \\
\hline Urine amino acids & 150 & Not diagnostic in any participant \\
\hline Urine creatinine & 13 & Not diagnostic in any participant \\
\hline Oligosaccharides & 12 & Not diagnostic in any participant \\
\hline Purine/pyrimidine studies & 30 & Often done after a marginally low uric acid, normal in all participants \\
\hline \multicolumn{3}{|l|}{ Cerebrospinal fluid tests } \\
\hline CSF glucose lactate & 58 & $\begin{array}{l}\text { Lactate raised in one boy investigated at } 1.4 \text { years of age with dysmorphia, } \\
\text { pulmonary stenosis, squint and hypertonia; MRS showed lactate peak } \\
\text { although respiratory chain enzymes normal and no genetic diagnosis of } \\
\text { mitochondrial disease made } \\
\text { Glucose low in two patients: a boy investigated at } 1.7 \text { years with } \\
\text { EDI, hypotonia, seizures and paroxysmal upgaze when fasted; a girl } \\
\text { investigated at } 1.9 \text { years with EDI, left hemiplegia and seizures. Both } \\
\text { confirmed to have mutations in Glut } 1 \text { deficiency syndrome gene }\end{array}$ \\
\hline CSF amino acids & 19 & $\begin{array}{l}\text { Diagnostic in two cases: a boy, investigated at } 4 \text { months of age for } \\
\text { developmental impairment, poor visual function, evolving dystonia } \\
\text { and microcephaly diagnosed with serine deficiency; a boy investigated } \\
\text { at } 0.8 \text { year for developmental impairment, poor visual function and } \\
\text { microcephaly whose plasma amino acids revealed low serine, ultimately } \\
\text { diagnosed with serine deficiency }\end{array}$ \\
\hline CSF neurotransmitters & 32 & Not diagnostic in any participant \\
\hline
\end{tabular}




\begin{tabular}{lcl}
\hline Table 3 Continued & & \\
\hline Investigation & No of participants (\% of total) & Comments \\
\hline CSF viral studies & 18 & Not diagnostic in any participant \\
Other & 2 & Not diagnostic in any participant \\
Skeletal survey & 9 & Not diagnostic in any participant \\
\hline Muscle biopsy & 2 & Sent for variety of tests-not diagnostic in any participant \\
\hline Fibroblast culture & & \\
\hline
\end{tabular}

ANA, antinuclear antibody; CSF, cerebrospinal fluid; EDI, early developmental impairment; LDH, lactate dehydrogenase; MRS, magnetic resonance proton spectroscopy.

test is low (£5.94). Given 469 participants were tested and three were positive for this diagnosis, two of whom showed improvement on treatment, the cost per diagnosis in our cohort was $£ 929$, which appears cost-effective given a treatment exists to improve outcome.

Plasma amino acids were diagnostic in $1.2 \%$ of our participants, all of whom had EDI+. Organic acids were abnormal in $0.9 \%$, two of whom had abnormal plasma amino acids. Urine Glycosaminoglycans (GAGs) revealed no diagnoses. Other metabolic investigations were performed in our cohort, outside of the guideline, but were rarely diagnostic. Because our participants with a positive result had EDI+, we do not recommend metabolic tests in EDI-. In children with EDI+, metabolic tests should be first line where concern exists about an inborn error of metabolism. ${ }^{3}$ Where no such concern exists, they should be second line, or performed if the presentation changes or other investigations point towards these conditions.

Microarray found a diagnosis in over $10 \%$ of our cases, with similar frequencies between EDI- and EDI+. We advocate microarray testing in all children with EDI. We recommend Fragile $\mathrm{X}$ testing if the microarray is normal in boys with consistent syndromal features or a child of either sex with a family history consistent with Fragile X. Where no diagnosis is found after initial investigations in children with EDI+ or a relevant family history, referral to a clinical geneticist should be considered. During the study period, the Clinical Genetics service recruited to the Deciphering Developmental Disorders (DDD) study, and we await the results of this study and the UK 100,000 genome project in investigating children with EDI.

The role of MRI in EDI is controversial, particularly as sedation or general anaesthetic is required for those who cannot lie still. Consensus statements in 1997 and 2003 recommended MRI only in children with EDI and additional symptoms based on a belief that children with EDI and no additional symptoms were unlikely to have structural brain abnormalities. ${ }^{15}$ There was a paucity of data to support this view. Our previous analysis data show varying rates of abnormality between EDI+ and EDI- groups. ${ }^{18} 32$ Our current data show that MR imaging has the highest diagnostic rates of any tests, with $13.3 \%$ in children without additional features and $24 \%$ in those with additional features. The lack of a statistical difference between groups is probably a type 2 statistical error.

Clinically, we advocate a common-sense approach. In a child with EDI-, MRI should not be a first-line test because of the anaesthetic risks and because of the yield of microarray and thyroid function. Where no diagnosis is found on first-line

Table 4 MRI abnormalities seen in our cohort

\begin{tabular}{|c|c|c|c|}
\hline MR abnormalities & All participants & EDI and no additional features & EDI and additional features \\
\hline \multicolumn{4}{|l|}{ Specific abnormalities likely to explain EDI or point towards a diagnosis } \\
\hline $\begin{array}{l}\text { Hypoxic ischaemic injury: } \\
\text { - Periventricular leukomalacia } \\
\text { - Central (predominately basal ganglia) } \\
\text { - Peripheral (predominately watershed areas) }\end{array}$ & 25 & 1 & 24 \\
\hline Toxic metabolic & 17 & 0 & 17 \\
\hline Brain malformation & 37 & 2 & 35 \\
\hline Phakomatoses/tumours & 3 & 1 & 2 \\
\hline Previous infection & 0 & 0 & 0 \\
\hline Hydrocephalus & 3 & 0 & 3 \\
\hline Total & 85 & 4 & 81 \\
\hline \multicolumn{4}{|l|}{ Specific or non-specific abnormalities not likely to explain EDI } \\
\hline Posterior fossa abnormalities, such as Chiari malformation & 6 & 1 & 5 \\
\hline Cavum septum pellucidum & 2 & 0 & 2 \\
\hline Under-opercularisation of the Sylvian fissure & 0 & 0 & 0 \\
\hline Reduced volume of white matter/grey matter & 21 & 2 & 19 \\
\hline Delayed myelination & 12 & 0 & 12 \\
\hline Non-specific white matter abnormality or focal gliosis & 30 & 2 & 28 \\
\hline Arachnoid cyst & 2 & 0 & 2 \\
\hline Optic nerve hypoplasia without evidence of septic optic dysplasia & 0 & 0 & 0 \\
\hline Subdural collection/effusion & 0 & 0 & 0 \\
\hline Non-specific MRS abnormalities & 2 & 1 & 1 \\
\hline Total & 75 & 6 & 69 \\
\hline
\end{tabular}

EDI, early developmental impairment. 


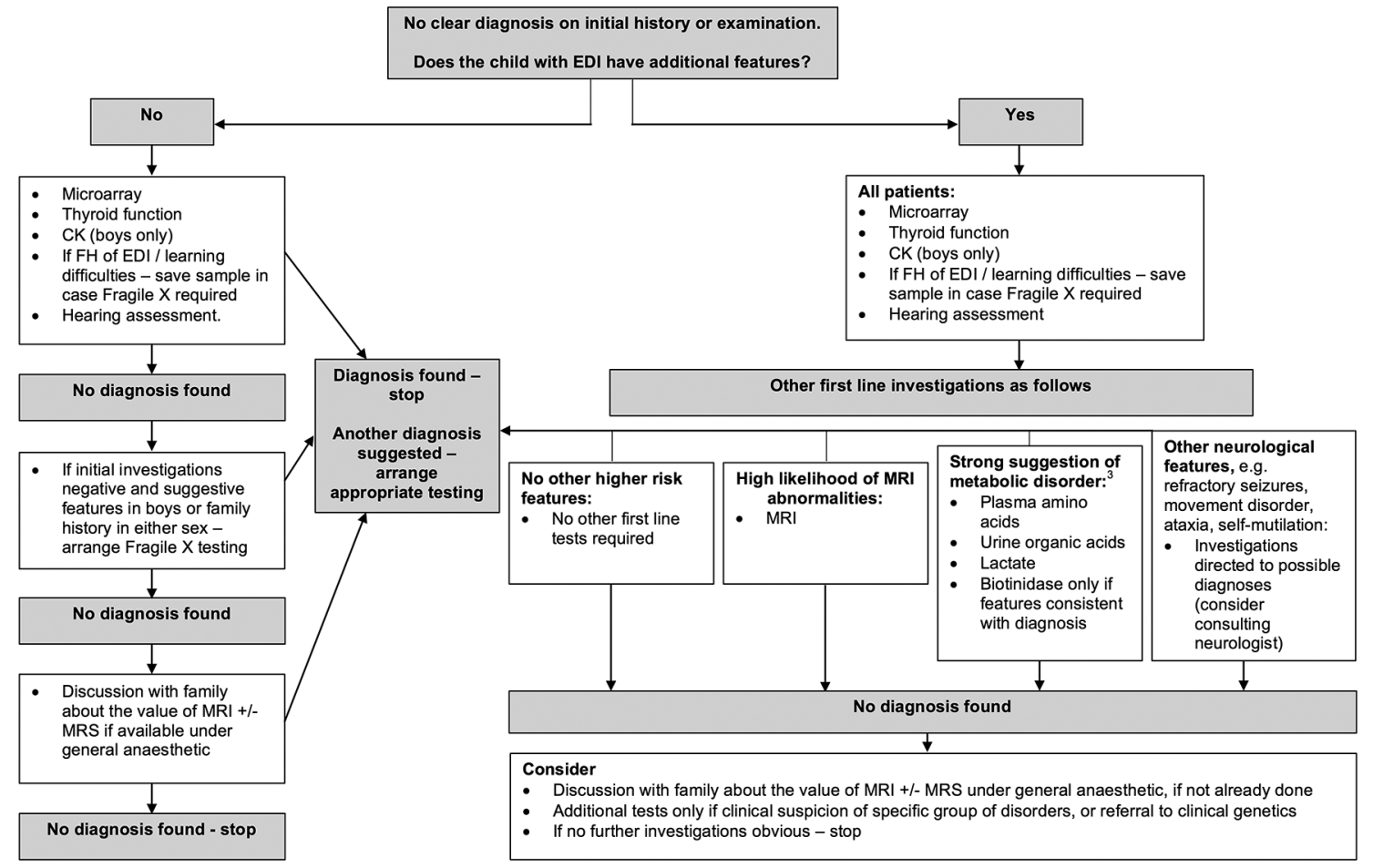

Figure 1 Guideline on how to investigate children with EDI. CK, creatine kinase; FH, family history; MRS, magnetic resonance proton spectroscopy. High likelihood of MRI abnormalities: skeletal dysplasia, signs of upper motor neuron involvement, refractory or focal seizures, ophthalmological signs, failure to thrive not explained by poor calorific input, antenatal concerns such as maternal drug use or hydrops, feeding/swallowing difficulties, gait or movement abnormalities, central mediated hypotonia, and airway problems like vocal cord palsy or central apnoea.

laboratory testing, MRI should be discussed with the family, including the likelihood that no specific treatment is available for any abnormality, and the risks of general anaesthesia.

In children with EDI+, MRI should be first line if a high risk of specific MRI abnormalities is likely: skeletal dysplasia, signs of upper motor neuron involvement, refractory or focal seizures, ophthalmological signs, failure to thrive not explained by poor calorific input, antenatal concerns such as maternal drug use or hydrops, feeding/swallowing difficulties, gait or movement abnormalities, central mediated hypotonia and airway problems. In other children, MRI could be second-line investigation if the parents wanted it or deferred. Where a genetic diagnosis is found, MRI is not necessary unless a specific indication exists that would change management.

Our unit performs MR spectroscopy in children with EDI to detect conditions like creatine deficiency. ${ }^{18}$ We found a case of creatine transporter deficiency using MRS, a child with large lactate peak suspected to have a defect in pyruvate metabolism, and a third participant with a non-specific reduction in choline levels. Because MRS adds only around $8 \mathrm{~min}$ to acquisition times, and creatine deficiencies are treatable, we recommend MRS for children with EDI when MRI is performed where it is available.

\section{Where no diagnosis is found}

If the initial screen of investigations prove negative, we would not recommend relentless investigations for increasingly rare conditions and the diagnostic voyage can cease. It may be beneficial for units to have a forum to discuss difficult cases, as the clinical experience of clinicians may vary: more experienced clinicians may recognise subtle clues to rare diagnoses, and geneticists may help identify dysmorphic features/diagnoses and facilitate access to single gene tests, gene exome studies or research projects. When a diagnostic voyage does end, the clinician should remember to review periodically whether new features have arisen or new technologies developed to help identify a cause.

\section{Limitations with our data}

As with previous retrospective data on the investigation of children with EDI, ${ }^{32}$ our data have methodological flaws. We relied on the documentation in medical notes and clinical letters to phenotype our participants, and it is possible that features may not have been documented. Many recommended investigations were not performed, and we do not know why clinicians ordered specific additional tests. It is possible that missing data from investigations that were not performed may have contributed towards a diagnosis. Clinical notes are the result of review in busy clinics, so no formal developmental assessment is available to confirm the diagnosis, assess severity, or domains affected. Furthermore, while the term EDI is usually reserved for preschool children under 5 years of age, we included older children. Our rationale for this was that it was likely these children would have been diagnosed with EDI and investigated if they had been in the UK. It is also debatable whether the term 'early', and the division of under and over 5 years of age, is relevant to diagnostic rates of investigations.

It is also possible that many factors may combine to affect a child's development. For example, anaemia or vitamin D deficiency, low parental educational ability and/or poor stimulation/ environment may each play an additive role. In these situations, medical treatment of any abnormalities found, such as mild to moderate anaemia or vitamin D deficiency, may lead to some improvement in development. Even though this may not return to the child's development level to 'normal', it may give a clinically significant improvement for the child, improving their sense 
of well-being and quality of life. While a proportion of children in our study had non-diagnostic abnormalities in investigations like full blood count, renal, liver function or vitamin D, the clinical notes did not reveal any child in whom treatment led to a significant improvement in developmental abilities. This may reflect our methodology and the limitations of relying on medical notes. Until future work shows if and how frequently this happens, we retain a strict definition as to what a diagnostic test is.

There is also a temptation in paediatrics to do as many tests as possible 'in one go' to avoid repeated venesection and to include screening tests. We do not support this approach. Our data suggest none of these tests revealed a cause, and it is not appropriate to manage or reassure a clinician's curiosity by performing investigations. Although we did not measure this in our cohort, a proportion of these 'screening tests' were not processed because of technical factors, such as the bottle leaked. Often this test was not thought sufficiently important to repeat, which questions why it was requested in the first place. In addition, other investigations were mildly abnormal or the results were of uncertain significance, which lead the child to having further investigations that were ultimately negative. Such distress could have been avoided if the initial investigation was not performed at all. Cost savings from not performing screening tests could be redirected to other areas of care, such as therapy or psychology.

\section{New recommendation on how to investigate EDI}

We propose a diagnostic algorithm in figure 1 based on our data. Guidelines cannot cover every clinical eventuality and should not stop clinicians ordering additional investigations where a high degree of suspicion exists about a specific condition.

\section{Future suggestions for research projects}

To truly determine which investigations are useful in making a diagnosis, a large prospective study is required in which children are phenotyped in detail and investigations are applied uniformly across the cohort. Secondary analysis could include whether the age at time of parent's first concern about their child's developmental level, the degree of developmental impairment and the pattern of domains affected affect which investigations are likely to be diagnostic. The role of newer technologies like gene exome studies and cost-efficiency analysis of investigation pathways could also be assessed.

\section{CONCLUSIONS}

Many recommended first-line investigations for EDI are rarely diagnostic and can be safely deferred without missing diagnoses. This has cost-saving implications to the NHS. We recommend a streamlined guideline based on our results, but a prospective study is required to provide robust evidence of the use of investigations according to additional features, level of developmental impairment and domains affected, which would enable the generation of an improved evidence-based guideline.

\section{Author affiliations}

'Department of Paediatric Neurology, Sheffield Children's Hospital NHS Foundation Trust, Ryegate Children's Centre, Sheffield, UK

${ }^{2}$ Department of Paediatric Neurodisability, Sheffield Children's Hospital NHS Foundation Trust, Ryegate Children's Centre, Sheffield, UK

${ }^{3}$ Department of Paediatrics, Sheffield Children's Hospital NHS Foundation Trust, Western Bank, Sheffield, UK

${ }^{4}$ Department of Paediatric Neuroradiology, Sheffield Children's Hospital NHS Foundation Trust, Sheffield, UK

${ }^{5}$ Clinical Trials Research Unit, School of Health and Related Research, University of Sheffield, Sheffield, UK

${ }^{6}$ Department of Community Paediatrics, Sheffield Children's Hospital NHS Foundation Trust, Sheffield, UK
${ }^{7}$ Department of Clinical Genetics, Sheffield Children's Hospital NHS Foundation Trust, Sheffield, UK

Contributors ARH designed/conceived the project, collated data from medical notes and investigation software, analysed data and drafted the paper. RS, MA, SA, SS, SB, NM, AR, MJP and DJAC significantly contributed to revising project design, identified participants, reviewed notes and investigation software to determine phenotype and the contribution made to diagnosis by investigations, reviewed and commented on data analysis, reviewed drafts of the paper and agreed on the final version. JC significantly contributed to reviewing study design and recommended changes to methodology, reviewed and assisted with data analysis and interpretation, assisted in drafting the paper and agreed on the final version submitted. All authors are accountable for the integrity and accuracy of the data submitted.

Competing interests None declared.

Provenance and peer review Not commissioned; externally peer reviewed.

(c) Article author(s) (or their employer(s) unless otherwise stated in the text of the article) 2017. All rights reserved. No commercial use is permitted unless otherwise expressly granted.

\section{REFERENCES}

1 Shevell M, Ashwal S, Donley D, et al. Practice parameter: evaluation of the child with global developmental delay: report of the Quality Standards Subcommittee of the American Academy of Neurology and The Practice Committee of the Child Neurology Society. Neurology 2003;60:367-80.

2 Majnemer A, Shevell MI. Diagnostic yield of the neurologic assessment of the developmentally delayed child. J Pediatr 1995;127:193-9.

3 Horridge KA. Assessment and investigation of the child with disordered development. Arch Dis Child Educ Pract Ed 2011;96:9-20.

4 Boyle CA, Boulet S, Schieve LA, et al. Trends in the prevalence of developmental disabilities in US children, 1997-2008. Pediatrics 2011;127:1034-42.

5 Curry CJ, Stevenson RE, Aughton D, et al. Evaluation of mental retardation: recommendations of a Consensus Conference: American College of Medical Genetics. Am J Med Genet 1997;72:468-77.

6 García-Cazorla A, Wolf NI, Serrano M, et al. Mental retardation and inborn errors of metabolism. J Inherit Metab Dis 2009;32:597-608.

7 Gillberg C. Practitioner review: physical investigations in mental retardation. J Child Psychol Psychiatry 1997;38:889-97.

8 Battaglia A, Bianchini E, Carey JC, et al. Diagnostic yield of the comprehensive assessment of developmental delay/mental retardation in an institute of child neuropsychiatry. Am J Med Genet 1999;82:60-6.

9 Gillberg C, Soderstrom H. Learning disability. Lancet 2003;362:811-21.

10 Jain S, Chowdhury V, Juneja M, et al. Intellectual disability in Indian children: experience with a stratified approach for etiological diagnosis. Indian Pediatr 2013;50:1125-30.

11 Jauhari P, Boggula R, Bhave A, et al. Aetiology of intellectual disability in paediatric outpatients in Northern India. Dev Med Child Neurol 2011;53:167-72.

12 McDonald L, Rennie A, Tolmie J, et al. Investigation of global developmental delay. Arch Dis Child 2006;91:701-5.

13 Poplawski NK. Investigating intellectual disability: a genetic perspective. J Paediatr Child Health 2003;39:492-506.

14 Shevell MI, Majnemer A, Rosenbaum P, et al. Profile of referrals for early childhood developmental delay to ambulatory subspecialty clinics. J Child Neurol 2001;16:645-50

15 van Karnebeek CD, Scheper FY, Abeling NG, et al. Etiology of mental retardation in children referred to a tertiary care center: a prospective study. Am J Ment Retard 2005;110:253-67.

16 Wilska ML, Kaski MK. Why and how to assess the aetiological diagnosis of children with intellectual disability/mental retardation and other neurodevelopmental disorders: description of the finnish approach. Eur J Paediatr Neurol 2001;5:7-13.

17 Hughes R, Sharma R, Connolly DJ, et al. Survey of UK attitudes and protocols for the investigation of early developmental impairment. J Paediatr Child Health 2017;53:318-20

18 Griffiths PD, Batty R, Warren D, et al. The use of MR imaging and spectroscopy of the brain in children investigated for developmental delay: what is the most appropriate imaging strategy? Eur Radiol 2011;21:1820-30.

19 Makela NL, Birch PH, Friedman JM, et al. Parental perceived value of a diagnosis for intellectual disability (ID): a qualitative comparison of families with and without a diagnosis for their child's ID. Am J Med Genet A 2009;149A:2393-402.

20 Wolf B. Biotinidase deficiency. In: Pagon RA, Adam MP, Ardinger HH, eds. GeneReviews. Seattle: University of Washington, 2000. www.ncbi.nlm.nih.gov/books/ NBK1322

21 Asgari A, Rouhi Dehnabeh S, Zargari M, et al. Clinical, biochemical and genetic analysis of biotinidase deficiency in Iranian population. Arch Iran Med 2016;19:774-8. 
22 Mukhopadhyay D, Das MK, Dhar S, et al. Multiple carboxylase deficiency (late onset) due to deficiency of biotinidase. Indian J Dermatol 2014;59:502-4.

23 Wolf $B$. Biotinidase deficiency should be considered in individuals exhibiting myelopathy with or without and vision loss. Mol Genet Metab 2015;116:113-8.

24 Raha S, Udani V. Biotinidase deficiency presenting as recurrent myelopathy in a 7-year-old boy and a review of the literature. Pediatr Neurol 2011;45:261-4.

25 Karimzadeh P, Ahmadabadi F, Jafari N, et al. Biotinidase deficiency: a reversible neurometabolic disorder (an Iranian pediatric case series). Iran J Child Neurol 2013;7:47-52.

26 Ogundele MO. Question 2. What is the incidence of biotin deficiency in preschool children with global developmental delay? Arch Dis Child 2011;96:895-7.

27 Searle AK, Baghurst PA, van Hooff M, et al. Tracing the long-term legacy of childhood lead exposure: a review of three decades of the port Pirie cohort study. Neurotoxicology 2014;43:46-56.
28 Hou S, Yuan L, Jin P, et al. A clinical study of the effects of lead poisoning on the intelligence and neurobehavioral abilities of children. Theor Biol Med Model 2013;10:13.

29 Chandramouli K, Steer CD, Ellis M, et al. Effects of early childhood lead exposure on academic performance and behaviour of school age children. Arch Dis Child 2009;94:844-8.

30 Pirkle JL, Brody DJ, Gunter EW, et al. The decline in blood lead levels in the United States. The National Health and Nutrition Examination Surveys (NHANES). JAMA 1994;272:284-91.

31 Centers for Disease Control and Prevention (CDC). Blood lead levels in children aged 1-5 years-United States, 1999-2010. MMWR 2013;61:245-8.

32 Hart AR, Batty R, Widjaja E, et al. MRI in children with global developmental delay-a retrospective case note review. J Paediatr Neurology 2011;9:15-21. 